\title{
Combined Analysis of Vascular Endothelial Growth Factor Expression with Cyclooxygenase-2 and Mast Cell Density in Oral Squamous Cell Carcinoma
}

\author{
Alireza Akbarzadeh Baghban ${ }^{a}$ Nasim Taghavi ${ }^{b}$ Maryam Shahla ${ }^{b}$ \\ ${ }^{a}$ Department of Basic Sciences, School of Rehabilitation Sciences, Shahid Beheshti University of Medical Sciences, \\ and ${ }^{b}$ Dental Research Center, Department of Oral and Maxillofacial Pathology, School of Dentistry, Shahid Beheshti \\ University of Medical Sciences, Tehran, Iran
}

\section{Key Words}

Cyclooxygenase- $2 \cdot$ Mast cell density $\cdot$ Oral squamous cell carcinoma $\cdot$ Vascular endothelial growth factor

\begin{abstract}
Background: Overexpression of vascular endothelial growth factor (VEGF) and cyclooxygenase-2 (COX-2) and increasing mast cell density (MCD) in premalignant and malignant oral lesions have been documented. However, their correlation with clinicopathologic parameters and survival rate in oral squamous cell carcinoma (OSCC) is not completely clear. This study aimed to assess these subjects. Methods: VEGF, COX-2, and mast cell tryptase expression were examined immunohistochemically in 57 cases of OSCC. The relationships between the markers' expression and clinicopathologic data were assessed using bivariate and multivariate analysis. $\boldsymbol{R e}$ sults: Spearman's rank correlation coefficient showed a significant correlation between VEGF and COX-2 expression $(r=0.462, p<0.001)$, as well as between VEGF expression and MCD $(r=0.306, p<0.001)$. Multivariate analysis showed no significant correlation between the markers' immunoexpression and overall survival (OS), but a significant correlation between mode of invasion and OS [hazard ratio 0.362 (95\% Cl: 0.138-0.974); $p=0.038]$ was observed. An associa-
\end{abstract}

tion between MCD and gender ( $p=0.042$ ) was also found, as $M C D$ was higher in males. Conclusion: The significant correlation of VEGF expression with COX-2 expression and MCD may represent the roles of COX-2 and MCD in tumor angiogenesis by modulating VEGF production. However, VEGF, COX-2, and MCD are not useful indicators to predict prognosis in OSCC. Nevertheless, the mode of invasion can be considered as an independent prognostic factor in OSCC patients.

(c) 2016 S. Karger AG, Basel

\section{Introduction}

For tumors to outgrow a size of $2 \mathrm{~mm}$ requires the formation of new microvasculature and angiogenesis [1]. Vascular endothelial growth factor (VEGF) is known as a powerful cytokine and fundamental regulator of tumor angiogenesis in a number of malignancies. It is also related to vascular permeability, vasoactive molecule production, and mast cell chemotaxis [2-4].

Mast cells are a group of immune cells that promote angiogenesis by producing VEGF, tryptase, IL-8, and TNF, which may accelerate tumor growth and invasion $[5,6]$. A number of studies have indicated that mast cells

\section{KARGER}

(c) 2016 S. Karger AG, Basel

E-Mail karger@karger.com

www.karger.com/pat 

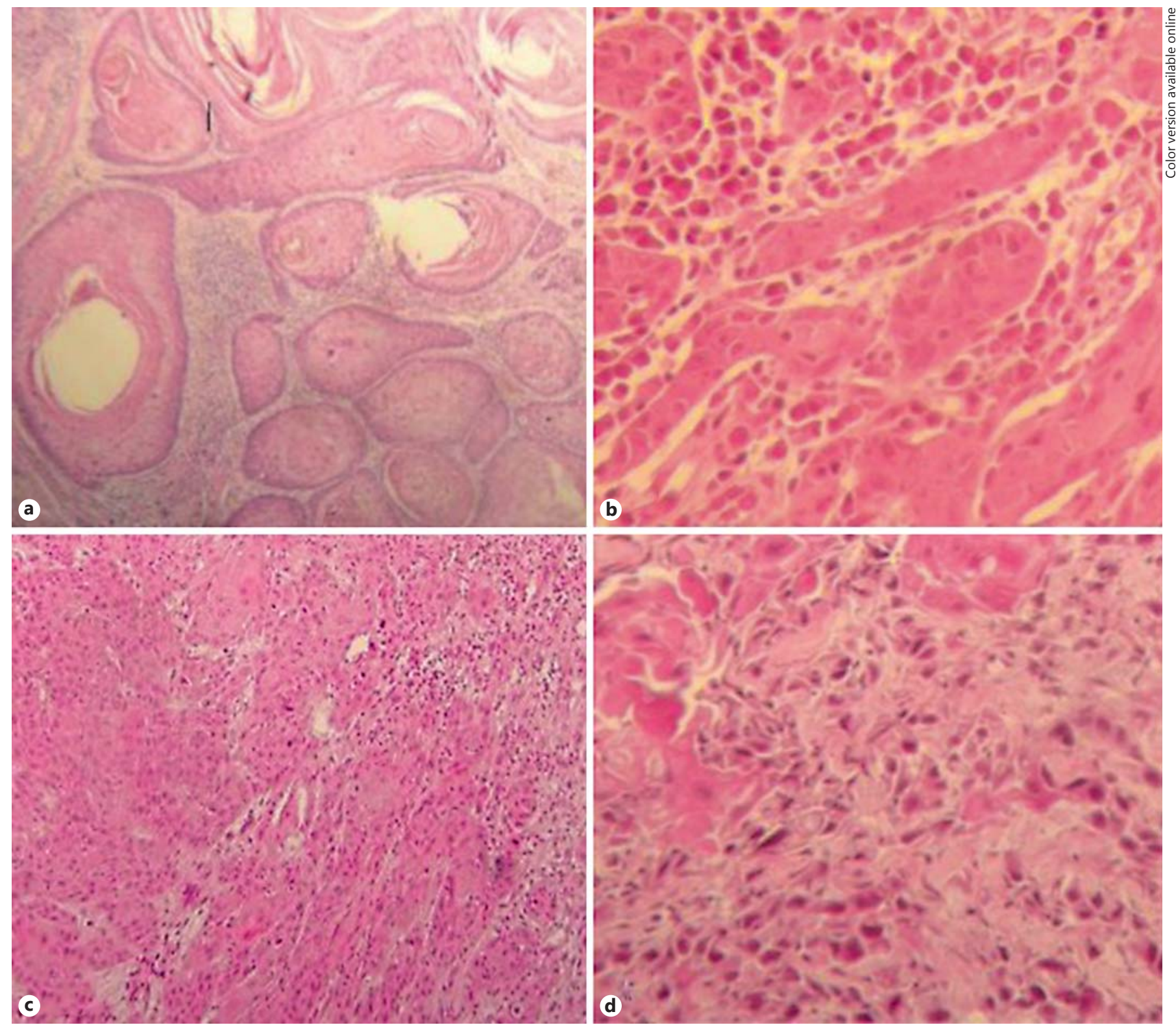

Fig. 1. Histologic mode of invasion: score I (a), score II (b), score III (c), and score IV (d).

restrict tumor growth by promoting collagen synthesis, inhibiting extracellular matrix degradation and stimulating IL-3 and IL-4 production. Increasing VEGF expression and mast cell density (MCD) between normal oral tissue, dysplasia, and oral squamous cell carcinoma (OSCC) have been reported. Moreover, MCD appears to be a prognostic indicator in some tumors $[7,8]$, but whether this is the case in OSCC is an issue of debate.

Cyclooxygenase-2 (COX-2) is a key enzyme not detectable in normal tissue, but can be induced by growth factors, inflammation, tumor oncogenes, and promoters. COX-2 overexpression has been documented in several types of neoplasia, including premalignant and malignant oral and skin lesions and human melanoma. COX2 overexpression may promote tumor growth by stimulating neovascularization and suppressing apoptosis [911 .

Recent studies have shown that mast cell tryptase can induce COX-2 expression by the specific cleavage of proteinase-activated receptor-2 (PAR-2) during early lip car- 
cinogenesis $[12,13]$. However, the correlation of COX-2 expression with MCD and prognosis in OSCC is not clear.

The present study aimed to investigate the correlation of MCD, VEGF, and COX-2 expression in the context of clinicopathologic parameters and survival rates in OSCC patients. The correlations between MCD and VEGF and COX-2 expression were also evaluated.

\section{Materials and Methods}

A total of 57 paraffin-embedded specimens from primary OSCC patients were collected from the archives of the Department of Oral and Maxillofacial Pathology, Shahid Beheshti University of Medical Sciences, Tehran, Iran. Clinicopathologic information on each case including sex, age, tumor location, survival rate, and mode of invasion was obtained from medical files and by reviewing slides. Cases without complete clinical data (especially survival rate), insufficient paraffin-embedded material, or incisional biopsies were excluded from the study.

For immunohistochemistry evaluation, $3-\mu \mathrm{m}$-thick sections of routinely processed paraffin blocks were prepared. Each section was deparaffinized, rehydrated in xylene and graded ethanol, and then treated with $3 \%$ hydrogen peroxide. Antigen retrieval was performed by microwaving the sections in citrate solution $(0.01 \mathrm{M}$, $\mathrm{pH}$ 6.0). After the slides were cooled to room temperature, they were incubated with the following primary antibodies for an hour: anti-mast cell tryptase monoclonal mouse antibody (Novocastra, Newcastle, UK) at a dilution of 1:100 for detecting mast cells, antiCOX-2 monoclonal mouse antibody (Novocastra) at 1:80, and anti-VEGF polyclonal rabbit antibody (BioGenex, Fremont, Calif., USA).

The sections were then washed with TBS and treated with Dako Envision $^{\mathrm{TM}}$. Diaminobenzidine chromogen (K3468; DAKO) was applied to visualize marker expression. The tissue sections were counterstained with Mayer's hematoxylin and observed under a light microscope.

Ulcerative colitis, hemangioma, and skin samples were used as positive controls for COX-2, VEGF, and mast cell tryptase, respectively.

COX-2 and VEGF immunoreactivity were scored using a semiquantitative method as follows: absent $(-)$, low $(+,<20 \%$ positive tumor cells), moderate $(++, 20-50 \%$ positive tumor cells) or diffuse $(+++,>50 \%$ positive tumor cells) [11].

MCD around the tumor tissue was assessed by counting cells positive for tryptase under a light microscope in five hot spot fields equivalent to an area of $0.2 \mathrm{~mm}^{2}$ on magnification $\times 400$ [14].

The mode of invasion of the samples according to the modified grading system of Jakobbson et al. was scored based on the shape, border, and growth pattern of tumor islands as follows on the H\&E slides: score I = well-defined borderline; score II = cords, less marked borderline; score III = groups of cells, no distinct border line, and score IV = diffuse growth (fig. 1) [15].

All H\&E and IHC slides were evaluated by two pathologists who had no knowledge of the clinical outcomes of the patients.

The data were stored and analyzed with the SPSS 18 software package (SPSS, IHC, Chicago, Ill., USA). Fisher's exact test, t test, logistic regression model and Spearman's correlation coefficient
Table 1. Clinicopathologic characteristics of patients with OSCC

\begin{tabular}{ll}
\hline Characteristics & \\
\hline Patients & 57 \\
Age, years & \\
$\quad$ Mean (SD) & $62.89(14.16)$ \\
$\quad$ Range & $34-91$ \\
Location & \\
$\quad$ Tongue & $25(43.8)$ \\
$\quad$ Buccal mucosa & $8(14.03)$ \\
Floor of mouth & $2(3.5)$ \\
$\quad$ Alveolar mucosa & $17(29.8)$ \\
$\quad$ Other & $5(8.7)$ \\
Mode of invasion & \\
$\quad$ Group 1 (scores I + II) & $40(70.2)$ \\
$\quad$ Group 2 (scores III + IV) & $17(29.8)$ \\
Survival time & \\
$\quad<24$ months & $20(35.08)$ \\
$24-48$ months & $8(14.03)$ \\
$>48$ months & $9(15.7)$ \\
\hline
\end{tabular}

Values represent total number of patients (\%), unless otherwise indicated.

were used to assess associations between MCD, VEGF, and COX2 expression and clinicopathologic variables.

Bivariate analysis with Kaplan-Meier curves was used to assess the survival rates of patients in different categories of VEGF and COX-2 expression. Multivariate analysis was performed according to Cox's regression model to estimate hazard ratios. The significance level was set at 0.05 .

\section{Results}

Fifty-seven patients with OSCC [ 27 males (47.3\%) and 30 females (52.7\%)] were studied. All patients were followed for an average of 29 months, with periods ranging from 10 to 85 months.

The mean and median overall survival (OS) times were 59.9 and 84 months, respectively. Twenty patients died of cancer, and 37 patients survived (table 1). The most frequent tumor site was the tongue (43.8\%), followed by the alveolar mucosa (29.8\%) and buccal mucosa (14.03\%). The distribution of the mode of invasion is presented in table 1.

Immunohistochemical evaluation of VEGF, COX-2, and mast cell tryptase were conducted. COX-2 expression was observed as cytoplasmic staining in tumor tissue (fig. 2). Of the 57 cases of OSCC, 36 (63.2\%) were identified as diffuse expression, $16(28.1 \%)$ as moderate expres- 


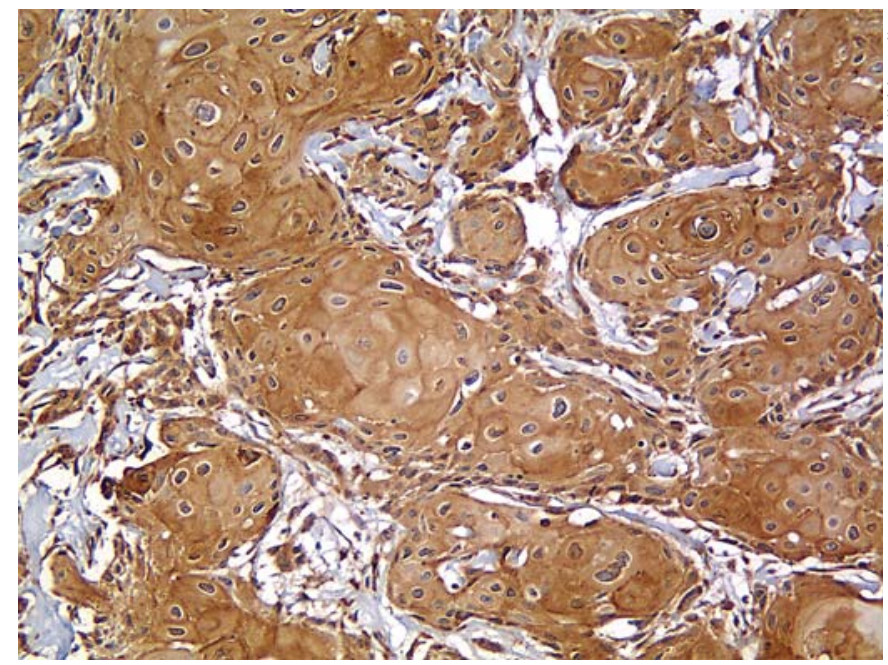

Fig. 2. Immunohistochemical staining (cytoplasmic) of COX-2 in OSCC $(\times 200)$.

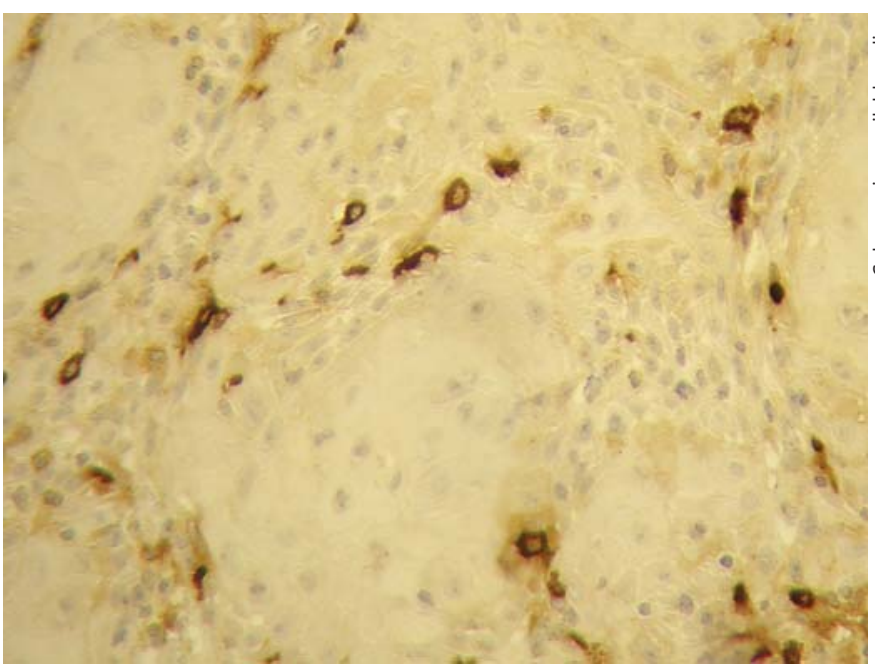

Fig. 4. Mast-cell-tryptase-positive cells in OSCC $(\times 400)$.

sion, and $5(8.8 \%)$ as low expression. VEGF expression was also observed as cytoplasmic staining (fig. 3) and mostly $(78.9 \%)$ as diffuse expression.

The mean MCD in the peritumoral area of OSCC samples was $0.783 \pm 1.186$ (range: $0.1-3.1$ ) (fig. 4 ).

No significant correlation was observed between VEGF or COX-2 expression and clinicopathologic variables. The only clinicopathologic variable that MCD significantly correlated with was gender $(\mathrm{p}=0.042)$, as MCD was higher in males.

VEGF, COX-2, and MCD in OSCC

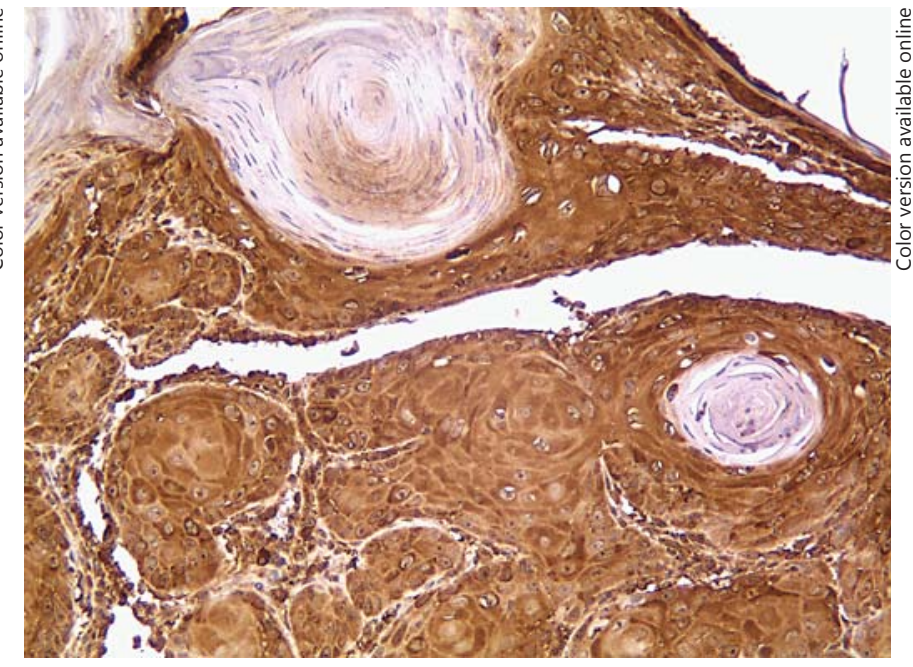

Fig. 3. Immunohistochemical staining (cytoplasmic) of VEGF in OSCC $(\times 200)$.

Kaplan-Meier analysis showed no significant differences in OS at different levels of VEGF expression (log-rank; $\mathrm{p}=0.266)$ (fig. 5) or COX-2 expression (log-rank; $\mathrm{p}=0.465)$ (fig. 6). The multivariate Cox regression analysis (including clinicopathologic parameters and immunoexpression markers) showed that only mode of invasion [hazard ratio 0.362 (95\% CI: 0.138-0.947); $\mathrm{p}=0.038$ ] correlated with OS (table 2), and can thus be considered as an independent prognostic factor in OSCC patients. Accordingly, the survival rate of patients within group 1 mode of invasion was 2.8 times $(1 / 0.362)$ greater than that in group 2.

Spearman's rank correlation coefficient analysis showed significant correlations between COX-2 and VEGF expression $(\mathrm{r}=0.426, \mathrm{p}<0.001)$ and between VEGF expression and MCD $(\mathrm{r}=0.360, \mathrm{p}=<0.001)$. No correlation between COX-2 expression and MCD ( $\mathrm{r}=$ $0.195, \mathrm{p}=0.146)$ was observed.

\section{Discussion}

Tumor angiogenesis is a complex process which is controlled by angiogenic and proangiogenic factors released from tumor cells and/or host immune cells. Among angiogenic polypeptides, VEGF has been identified as a major factor underlying tumor proliferation and pathological angiogenesis [3, 16-18].

Previous studies that investigated angiogenesis in OSCC have shown correlations between microvessel den-

Pathobiology 2017;84:80-86 


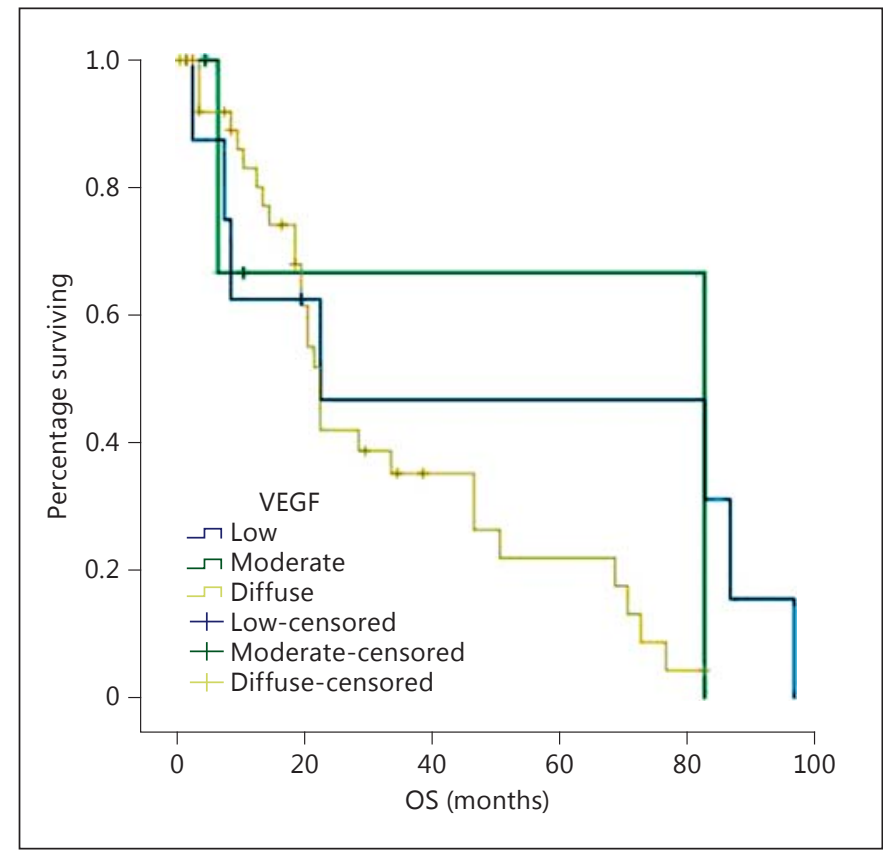

Fig. 5. Correlation between VEGF expression and OS.

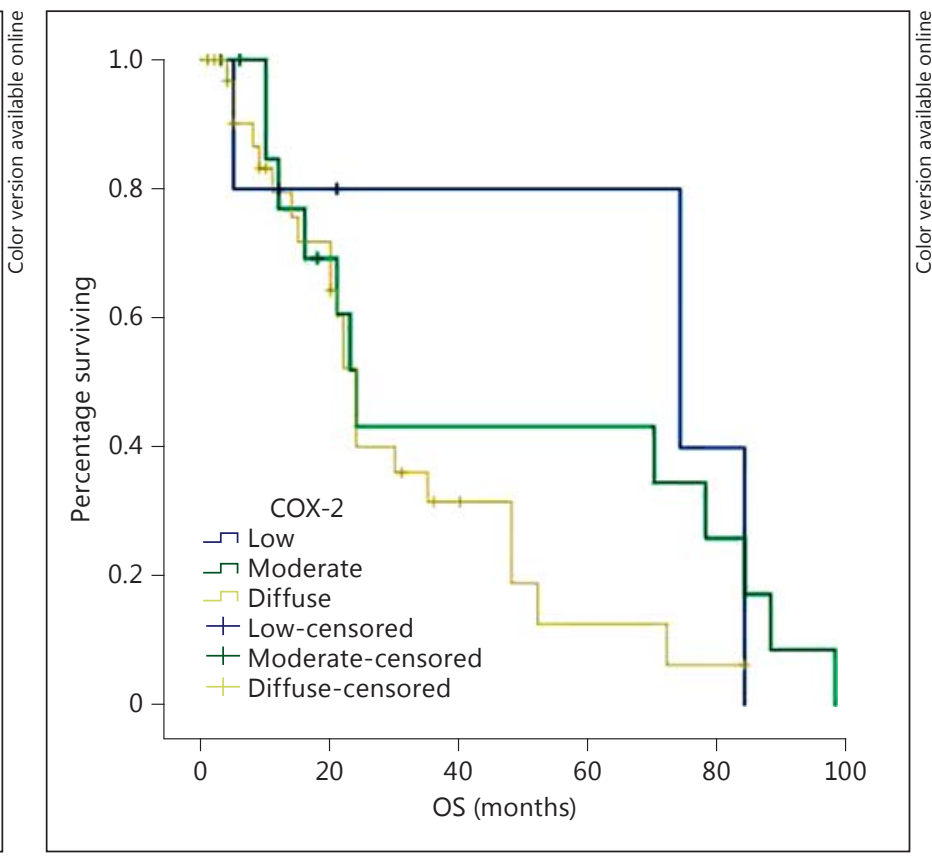

Fig. 6. Correlation between COX-2 expression and OS.
Table 2. Multivariate analysis of prognostic factors of survival using Cox's proportional hazard model

\begin{tabular}{lclll}
\hline Parameters & Coefficient (SE) & $\mathrm{p}$ & Hazard ratio & 95\% CI \\
\hline Age & $0.13(0.018)$ & 0.482 & 1.013 & $0.997-1.050$ \\
Sex $^{\mathrm{a}}$ & $0.523(0.513)$ & 0.309 & 1.69 & $0.617-4.613$ \\
Tumor location & - & 0.504 & - & - \\
Mode of invasion & $-1.017(0.491)$ & $0.038^{*}$ & 0.362 & $0.138-0.947$ \\
VEGF expression & $0.519(0.478)$ & 0.278 & 1.680 & $0.658-4.288$ \\
COX-2 expression & $0.053(0.478)$ & 0.896 & 1.054 & $0.475-2.341$ \\
MCD & $0.111(0.307)$ & 0.719 & 1.117 & $0.612-2.039$ \\
\hline
\end{tabular}

${ }^{\text {a }}$ Reference category: male. ${ }^{*} \mathrm{p}<0.05$. sity, VEGF expression, and MCD, suggesting a possible role for mast cells in tumor progression by regulating angiogenesis $[2,8,14,19,20]$. Lymph node metastasis in head and neck cancer was shown to be correlated with COX-2 and VEGF expression, which indicates a central role for the COX-2 pathway in angiogenesis [11].

In the current study, we showed significant positive correlations between VEGF and COX-2 expression and between VEGF expression and MCD. These findings stress the roles of mast cells and COX-2 in angiogenesis through the modulation of VEGF production.

Rojas et al. [12] indicated that COX-2 overexpression is a key event in the early stage of UV-induced premalig- nant and malignant skin lesions, which is associated with increased MCD and PAR-2 expression. In vitro studies have also demonstrated upregulation of COX-2 and PAR-2 in cultured keratinocytes under UV radiation [21, $22]$. The results of our study indicated no correlation between MCD and COX-2 expression. This finding may be due to differences in etiologic factors, stage of disease in our study compared with previous studies, and the probable role of PAR-2 in the COX-2 pathway.

In our series, a significant correlation between MCD and gender was observed, as males had a higher MCD. Animal research has shown an increase in MCD in male rat jejunums following electrical stimulation [23] and 
also in frogs following androgen administration [24]. These findings may represent the role of hormones in this process. However, further studies investigating the roles of sex hormones in MCD around tumor tissue and the possible therapeutic effects of these hormones are recommended.

Assessing the relationships between clinicopathologic parameters and OS showed that only mode of invasion is an independent prognostic factor of OS. This finding was in accordance with those of previous studies [25-27], but no relationships between mode of invasion and MCD, VEGF, and COX-2 expression were found. Mode of invasion is a histologic parameter characterized by the number of tumor cells in islands, the borders and shapes of tumor islands, and the growth patterns. Mode of invasion represents the biologic mechanisms of cell motility and adhesion. Regarding the findings in the literature and those of the present study, poor outcome and aggressive behavior of tumors are predicted for tumors with an unfavorable mode of invasion [25-28].

To date, the contributions of the overexpression of COX-2 and of mast cells to tumor invasion have been shown in carcinomas of the breast, esophagus, colon, and lung [29-35]. This was the first attempt to characterize the correlations between COX-2 expression and MCD with OS. Our results indicated no association between COX-2 expression and OS, which was consistent with the results of Turk et al. [36] and Tsubochi et al. [32] in studies of lung cancer. They also did not find correlations between COX-2 expression and clinical stage, histologic grade, or lymph node metastasis, suggesting that COX-2, despite its significant role in tumor angiogenesis, cannot be regarded as a prognostic factor in cancer. COX-2 may be involved in the early stage of carcinogenesis.

The lack of a correlation between MCD and OS seen in current study was similar to the findings of previous studies in colon carcinoma [33]. Discordant results regarding this possible correlation have been demonstrated in rectal carcinoma [7]. It is difficult to justify the discrepancy with respect to the correlation between MCD and OS in different tumors. Evidence shows that mast cells may be recruited by tumor-derived chemoattractants, which could influence mast cell responses. Reed et al. [37] reported a remarkable increase in MCD surrounding melanocytic lesions expressing IL-3 and IL-3a on mast cells. Furthermore, the cytotoxic activity of mast cells for some tumors (especially those sensitive to TNF- $\alpha$ ) due to increasing cytotoxic activation or cytotoxic products released by peritumoral macrophages and eosinophils has been well documented [7]. Therefore, mast cell activity and MCD may be affected by unknown chemoattractants and components of the stroma in OSCC, an issue that requires more research.

In agreement with the findings of Mehta et al. [38] and in contrast to the findings of previous studies conducted on esophageal and oropharyngeal squamous cell carcinoma $[39,40]$, we did not find a relationship between VEGF expression and OS. This may be attributed to differences between our study and previous studies in the types of tumors analyzed, the types of studies performed, and greater sample size in their studies.

In conclusion, the significant correlation of VEGF expression with COX-2 expression and MCD may represent the role of COX-2 and MCD in tumor angiogenesis by modulating VEGF production. However, VEGF, COX-2, and MCD are not useful indicators of prognosis in OSCC. Nevertheless, mode of invasion can be considered as an independent prognostic factor in OSCC patients. The significant correlation between MCD and gender, which is a new and interesting finding, suggests a possible role for sex hormones in this scenario. However, further investigation is required.

\section{Acknowledgements}

This work has been excerpted from postgraduate dissertation No. 676, supervised by Dr. Nasim Taghavi, Dental Faculty, Shahid Beheshti University of Medical Sciences, and financially supported by the Dental Research Center of Shahid Beheshti University of Medical Sciences.

References

1 Homer JJ, Greenman J, Stafford ND: Angiogenesis in head and neck squamous cell carcinoma. Clin Otolaryngol Allied Sci 2000;25: 169-180.

2 Michailidou EZ, Markopoulos AK, Antoniades DZ: VEGF expression from human dysplastic or malignant oral epithelium may be related to mast cell density and the subsequent angiogenetic phenomena. Int J Oral Maxillofac Surg 2012;41:1467-1473.

3 Ciurea R, Mărgăritescu C, Simionescu C, Stepan A, Ciurea M: VEGF and his R1 and R2 receptors expression in mast cells of oral squamous cells carcinomas and their involvement in tumoral angiogenesis. Rom J Morphol Embryol 2011;52:1227-1232.

4 Nayak S, Goel MM, Chandra S, Bhatia V, Mehrotra D, Kumar S, Makker A, Rath SK, Agarwal SP: VEGF-A immunohistochemical and mRNA expression in tissues and its serum levels in potentially malignant oral lesions and oral squamous cell carcinomas. Oral Oncol 2012;48:233-239. 
5 Kamal R, Dahiya P, Goyal N, Kumar M, Sharma N, Saini HR: Mast cells and oral pathologies: a review. J Nat Sci Biol Med 2015;6:3539.

6 Ch'ng S, Sullivan M, Yuan L, Davis P, Tan ST: Mast cells dysregulate apoptotic and cell cycle genes in mucosal squamous cell carcinoma. Cancer Cell Int 2006;6:28.

7 Grizzi F, Franceschini B, Chiriva-Internati M, Liu Y, Hermonat PL, Dioguardi N: Mast cells and human hepatocellular carcinoma. World J Gastroenterol 2003;9:1469-1473.

8 Elpek GO, Gelen T, Aksoy NH, Erdoğan A, Dertsiz L, Demircan A, Keleş N: The prognostic relevance of angiogenesis and mast cells in squamous cell carcinoma of the oesophagus. J Clin Pathol 2001;54:940-944.

9 Shibata M, Kodani I, Osaki M, Araki K, Adachi $\mathrm{H}$, Ryoke K, Ito H: Cyclo-oxygenase- 1 and -2 expression in human oral mucosa, dysplasias and squamous cell carcinomas and their pathological significance. Oral Oncol 2005; 41:304-312.

10 Pires I, Garcia A, Prada J, Queiroga FL: COX1 and COX-2 expression in canine cutaneous, oral and ocular melanocytic tumours. J Comp Pathol 2010;143:142-149.

11 Gallo O, Franchi A, Magnelli L, Sardi I, Vannacci A, Boddi V, Chiarugi V, Masini E: Cyclooxygenase-2 pathway correlates with VEGF expression in head and neck cancer. Implications for tumor angiogenesis and metastasis. Neoplasia 2001;3:53-61.

12 Rojas IG, Martínez A, Brethauer U, Grez P, Yefi R, Luza S, Marchesani FJ: Actinic cheilitis: epithelial expression of COX-2 and its association with mast cell tryptase and PAR-2. Oral Oncol 2009;45:284-290.

13 Rojas IG, Boza YV, Spencer ML, Flores M, Martínez A: Increased fibroblast density in actinic cheilitis: association with tryptasepositive mast cells, actinic elastosis and epithelial p53 and COX-2 expression. J Oral Pathol Med 2012;41:27-33.

14 Mohtasham N, Babakoohi S, Salehinejad J, Montaser-Kouhsari L, Shakeri MT, Shojaee S, Sistani NS, Firooz A: Mast cell density and angiogenesis in oral dysplastic epithelium and low- and high-grade oral squamous cell carcinoma. Acta Odontol Scand 2010;68:300-304.

15 Lund C, Sogaard H, Elbrond O, Jorgensen K, Andersen AP: Epidermoid carcinoma of the tongue. Histologic grading in the clinical evaluation. Acta Radiol Ther Phys Biol 1975;14: 513-521.

16 López-Graniel CM, Tamez de León D, Meneses-García A, Gómez-Ruiz C, Frias-Mendivil M, Granados-García M, Barrera-Franco JL: Tumor angiogenesis as a prognostic factor in oral cavity carcinomas. J Exp Clin Cancer Res 2001;20:463-468.
17 Williams JK, Carlson GW, Cohen C, Derose PB, Hunter S, Jurkiewicz MJ: Tumor angiogenesis as a prognostic factor in oral cavity tumors. Am J Surg 1994;168:373-380.

18 Forootan SS, Jones AS, Helliwell TR: Neoangiogenesis and squamous cell carcinoma of the tongue. Cancer 1999;23:137-146.

19 Ribatti D, Crivellato E: The controversial role of mast cells in tumor growth. Int Rev Cell Mol Biol 2009;275:89-131.

20 Sawatsubashi M, Yamada T, Fukushima N, Mizokami H, Tokunaga O, Shin T: Association of vascular endothelial growth factor and mast cells with angiogenesis in laryngeal squamous cell carcinoma. Virchows Arch 2000;436:243-248.

21 Buckman SY, Gresham A, Hale P, Hruza G, Anast J, Masferrer J, Pentland AP: COX-2 expression is induced by UVB exposure in human skin: implications for the development of skin cancer. Carcinogenesis 1998;19:723729.

22 Scott G, Deng A, Rodriguez-Burford C, Seiberg M, Han R, Babiarz L, Grizzle W, Bell W: Pentla Protease-activated receptor 2, a receptor involved in melanosome transfer, is upregulated in human skin by ultraviolet irradiation. J Invest Dermatol 2001;117:14121420 .

23 Gottwald T, Becker HD, Stead RH: Sex differences in neuromodulation of mucosal mast cells in the rat jejunum. Langenbecks Arch Chir 1997;382:157-163.

24 Di Matteo L, Vitiello II, Minucci S: Effects of sex steroid hormones and their antagonists on mast cell number in the testis of the frog, Rana esculenta. Zygote 2000;8:225-234.

25 Dissanayaka WL, Pitiyage G, Kumarasiri PV, Liyanage RL, Dias KD, Tilakaratne WM: Clinical and histopathologic parameters in survival of oral squamous cell carcinoma. Oral Surg Oral Med Oral Pathol Oral Radiol 2012;113:518-525.

26 Almangush A, Bello IO, Keski-Säntti H, et al: Depth of invasion, tumor budding, and worst pattern of invasion: prognostic indicators in early-stage oral tongue cancer. Head Neck 2014;36:811-818

27 Søland TM, Brusevold IJ, Koppang HS, Schenck K, Bryne M: Nerve growth factor receptor (p75 NTR) and pattern of invasion predict poor prognosis in oral squamous cell carcinoma. Histopathology 2008;53:62-72.

28 Taghavi N, Bagheri S, Akbarzadeh A: Prognostic implication of CD57, CD16, and TGF- $\beta$ expression in oral squamous cell carcinoma. J Oral Pathol Med 2016;45:58-62.
29 Tsujii M, Kawano S, Tsuji S, Sawaoka H, Hori $\mathrm{M}, \mathrm{DuBois} \mathrm{RN}$ : Cyclooxygenase regulates angiogenesis induced by colon cancer cells. Cell 1998;93:705-716.

30 Zimmermann KC, Sarbia M, Weber AA, Borchard F: Cyclooxygenase-2 expression in human esophageal carcinoma. Cancer Res 1999; 59:198-204.

31 Chan G, Boyle JO, Yang EK, Zhang F, Sacks PG: Cyclooxygenase-2 expression is up-regulated in squamous cell carcinoma of the head and neck. Cancer Res 1999;59:991-994.

32 Tsubochi H, Sato N, Hiyama M, Kaimori M, Endo S, Sohara Y, Imai T: Combined analysis of cyclooxygenase-2 expression with p53 and Ki-67 in nonsmall cell lung cancer. Ann Thorac Surg 2006;82:1198-1204

33 Lachter J, Stein M, Lichtig C, Eidelman S: Mast cells in colorectal neoplasias and premalignant disorders. Dis Colon Rectum 1995;38: 290-293.

34 Niczyporuk M, Hermanowicz A, Matuszczak E, Dziadziuszko R, Knaś M, Zalewska A, Chyczewski L: A lack of correlation between mast cells, angiogenesis, and outcome in non-small cell lung cancer. Exp Lung Res 2012;38:281285

35 Tinge B, Molin D, Bergqvist M, Ekman S, Bergström S: Mast cells in squamous cell esophageal carcinoma and clinical parameters. Cancer 2010;7:25-29.

36 Turk HM, Camci C, Sevinc A, Bukyukberber S, Sari I, Adli M: Cyclooxygenase-2 expression is not a marker of poor survival in lung cancer. Asian Pac J Cancer Prev 2012;13:315318.

37 Reed JA, McNutt NS, Bogdany JK, Albino AP: Expression of the mast cell growth factor interleukin-3 in melanocytic lesions correlates with an increased number of mast cells in the perilesional stroma: implications for melanoma progression. J Cutan Pathol 1996;23:495505 .

38 Mehta S, Moon J, Hashmi M, Leblanc M, Huang $\mathrm{CH}$, Rinehart E, Wolf GT, Urba SG, Banerjee SK, Williamson S: Predictive factors in patients with advanced and metastatic squamous cell carcinoma of the head and neck: a study based on SWOG protocol S0420. Oncol Rep 2013;29:2095-2100.

39 Smith BD, Smith GL, Carter D, Sasaki CT, Haffty BG: Prognostic significance of vascular endothelial growth factor protein levels in oral and oropharyngeal squamous cell carcinoma. J Clin Oncol 2000;18:2046-2052.

40 Hou X, Wei JC, Fu JH, Wang X, Luo RZ, He JH, Zhang LJ, Lin P, Yang HX: Vascular endothelial growth factor is a useful predictor of postoperative distant metastasis and survival prognosis in esophageal squamous cell carcinoma. Ann Surg Oncol 2015;22:3666-3673. 